\title{
Introduction: Arab Middle East states and societies in transition
}

The invasions of Iraq and Afghanistan, the 'War on Terror', the Palestinian elections, the Syrian withdrawal from Lebanon, and economic growth in Islamic Asia, have all unleashed forces that will be difficult to contain. Likewise, globalisation, the spread of new media, the natural and unnatural turnover of long-time leaders in many authoritarian societies, and youth bulges, among other factors, continue to erode the status quo. Whether the West advocates it or not, political change, and not always positive change, will be the result of these old and new forces. ${ }^{1}$

Anthony Bubalo, Greg Fealy and Whit Mason, 2008.

The Middle East is evolving in a world which is both globalizing and unequal. We are not witnessing a simple remodelling of the region's economic and political systems according to Western norms and values. There is, instead, a highly complex process under way of accommodation, reaction, and resistance to what is mostly regarded within the region as being a far from benign process. Changes in Arab society, particularly in urban areas, are reflected in falling birth rates, improving levels of literacy, changing consumer tastes and fashions, and the recent phenomenon of political blogging.

These changes have come about, however, within a framework of ongoing political authoritarianism and with high levels of insecurity at the societal level. The political, economic and social issues confronting the region have implications extending beyond the borders of the countries concerned.

Each Arab country is unique. Though they share important similarities in terms of their language, historical experience and Arab Muslim identity and values, they are each distinctive societies whose individual characteristics highlight the variety of historical, political and social experience of the Arab world. And yet, within that complex and evolving environment it is possible to draw broad distinctions between Egypt and the other Levant countries on the one hand, and their Arab counterparts in the Persian Gulf.

Some similarities and commonalities exist, of course. But contrasts appear between them in terms of their sources of wealth (oil-based versus predominantly non-oil economies) and political institutions (evolving 
traditional rule versus constitutional monarchies and Arab republics). The outlook, strategic orientation and values of the Levant countries and Egypt have been influenced by their distinctive Mediterranean cultural and commercial heritage, including the impact of European interventions. There are differences between the two groupings in terms of how they see themselves, and how they measure their accomplishments against the standards of others.

Exploring such differences and commonalities, which would be the fitting subject matter of another book, is not the purpose of this study. The specific focus of this book is on Egypt, and to a lesser extent Syria and Jordan - collectively referred to in this book as the Arab Middle East - as opposed to the Gulf and North African Arab states. And within the Arab Middle East context the analysis will focus very largely on Egypt, because of its importance in terms of population, political weight and Arab cultural impact. One in every four Arabs is an Egyptian. In 2008, in terms of GDP, Egypt had the third largest economy in the Arab world, after Saudi Arabia and the United Arab Emirates. It has some of the best-resourced and most innovative telecommunications and construction companies in the region. And although the future of the Arab world cannot be determined by any single country, the success or failure of Egypt speaks volumes about the evolving nature of Arab societies and their capacity to respond and engage, at different levels, with socioeconomic trends and institutions beyond the Arab world. If Egypt leads, most other Arab states will follow. If it can succeed, others should be able to succeed. If it fails, the consequences will be far-reaching.

\section{CONTEXT}

For many commentators, including some within the region, the shadow of the future hangs ominously over Egypt and the Arab Middle East. Indeed, unlike their counterparts in the Gulf, the fear of their failure will help to sustain a high level of international attention to the countries of the region in the coming decade. If one focusses largely on the contemporary political environment - the intractability of the Israeli-Palestinian conflict, the Iranian ascendancy in the regional order, the uncertainty surrounding the outlook for Iraq, the scale of demographic challenges, its chronic corruption and political stagnation and its strategic concerns, any sensible assessments of the prospects for the Arab Middle East are likely to be guarded, or worse.

The Arab Middle East region has been marked by profound social changes since the First World War, especially among the urban middle 
classes. The region's urban population as a whole appears to have increased from less than 15 million in 1950 to 84 million in 1980 . It now stands at around 173 million. Almost 25 per cent of the Arab population will soon live in cities of one million or more, affecting traditional social structures and safety nets. ${ }^{2}$

Arab societies have been witness to the impact of foreign occupation or dominance; the rise of nationalist, secular leftist and Islamist reform movements; changing gender roles (including female education and paid employment); and - depending on levels of education and social context - the gradual erosion of patriarchal authority. ${ }^{3}$ The political dynamics of Egypt, Jordan and Syria and the traditional status of military and security elites display strong elements of continuity. There is a strong disconnect between rulers and ruled. But in Egypt and elsewhere the business climate is changing as governments step up their efforts to reform and modernize economies.

Major contemporary trends include the Islamist movement - a complex phenomenon whose inclinations in some quarters towards ideologicallydriven self-righteousness, intolerance and exclusivity are exacerbated when Arab regimes are unable or unwilling to look beyond repression as their preferred response to its undoubted mobilizing capacity. ${ }^{4}$ Closely linked to the rise of the Islamist movement is the widening gap between the aspirations of literate and educated Arab youth and the realities of their daily circumstances. The benefits of the boom in oil prices are being felt unevenly across the region, both between countries and within Arab societies. $^{5}$

Across the Arab Middle East there is a deeply entrenched culture of non-accountability, and frequently also of corruption. Unlike authoritarian societies such as China, the Arab world has not demonstrated much determination to innovate. There is no secular liberal political force to capture the imagination of the Arab middle class. It is difficult to recall a time when societal tensions were higher.

Unlike the situation in many Western countries struggling to maintain their fertility rates at replacement levels, Arab states are dealing with a population explosion. And the implacable momentum of the demographic trends of the Arab Middle East makes economic reform inescapable, in Egypt and in other Arab countries as well, if governments are to meet the challenges of generating jobs, meeting demand for infrastructure, water and food, and sustaining political and social stability.

In addition to the infrastructural and social challenges posed by rapidly growing populations, demography also interacts directly with ecological issues, both in terms of the pressures of rising populations on water and land, and in shaping the effects of global warming. The projected rise 
in and ageing of Arab populations through to 2050 is expected to coincide with displacement of significant numbers of farmers in Egypt and pastoralists (especially in the lower Nile delta area of Egypt, as well as in the semi-arid regions of Syria) as the negative consequences of global warming for traditional agricultural and pastoral practices become more obvious. Tourism will suffer as Red Sea coral reefs degenerate. Suez Canal revenues will also be affected as northerly shipping routes become more available between North East Asia and Europe.

To cope with these developments, governments will have to strengthen the export sectors of their economies so overall food and water security can be maintained through food imports. ${ }^{6}$ Egypt and Syria will also have to find inclusive growth strategies which adapt and reform practices in agriculture, which represents the major source of income for much of their populations, and the single most important source of employment for the landless, the poor and for women.

In recent decades regional peace, access to foreign direct investment and United States (US) and European markets, growing exposure to international commercial realities, and the injection of private sector experience into both government and business have each helped to shape the economic future of Arab Middle East countries in positive directions. However, while there have been some welcome developments at times in the areas of popular participation in elections and various forms of political expression, there has been little real change in the political landscape accompanying changes in economic approach.

For reasons which arise from the political particularities of the Arab world, Arab states achieve markedly lower levels of performance against various measures of democracy than non-Arab Muslim countries. Islam, by itself, cannot explain that phenomenon. ${ }^{7}$ The problem, as Amr Hamzawy and Nathan Brown have observed, is that although the political culture of the Arab world is changing, democracies 'are not built in salons and on satellite channels' ${ }^{8}$ And even if certain economic processes are changing, the values underlying those processes, such as transparency and accountability and inclusiveness - which are essentially political values - are not manifesting themselves to any significant extent in Arab Middle East countries.

Arab governments face formidable challenges in closing the gaps between their levels of achievement and those of the remainder of a globalizing world. Vast quantities of information have to be distilled, validated, considered and acted upon. Addressing and responding to global challenges such as climate change, energy security, proliferation of weapons of mass destruction, pandemic diseases and transnational crime requires collective action internationally by governments, and 
collaborative efforts domestically and regionally. Governments have to work towards expanding international trading conditions and market opportunities. In circumstances where existing mechanisms of government are often of limited effectiveness, there are obvious difficulties in regard to the sharing of information and the synchronization of policy processes across government agencies, business and civil society.

Increasingly sophisticated, critical and articulate circles of influence within the region are expecting governments to come forward with policies to remove infrastructural and regulatory impediments to growth and reform, and to stimulate innovation and research. ${ }^{9}$ If they are to respond effectively to the demographic and other challenges, governments need to play a part in fostering a competitive business environment, with appropriate access to legal systems and financial mechanisms that encourage commercial initiative, including among small and medium sized businesses. ${ }^{10}$ And they need to be able to implement policies of reform, and create space for emerging entrepreneurs to compete with established circles of privilege, often in the teeth of informal and institutional resistance to change.

But reform is "hampered by chronic weaknesses in the government bureaucracy, defective judicial systems, a lack of political transparency or accountability and the vested interests of those who benefit from the existing arrangements. ${ }^{11}$ Ottaway and Dunne observe that the five sons of Arab rulers who succeeded their fathers after 1995 - Emir Hamad bin Khalifa al-Thani in Qatar; King Muhammad VI in Morocco; King Abdullah II in Jordan; King Hamad bin Isa al-Khalifa in Bahrain, and President Bashar al-Asad in Syria - each foreshadowed reform and appeared to see themselves as modernizers, but failed to pursue transformational political agendas. ${ }^{12}$ Jordan has not become more liberal under King Abdullah II, and the 'Damascus spring' which was anticipated in Syria after Bashar al-Asad became president in June 2000 did not last long. ${ }^{13}$ There are not many commentators who are confident the quality of political leadership will be sufficient to cope with the challenges ahead. ${ }^{14}$

Meanwhile, there are conflicting demands for both individual and community empowerment and for the preservation of core societal values, including Islam. There is a complex, shifting debate within Islamic groups, under pressure to choose between accommodation and confrontation with governments. There are divisions between those Islamists who are inclined to follow a literalist reading of the Koran and sayings (hadith) attributed to the Prophet Mohammed; those salafists who seek to combine literalist approaches to the Koran and hadith with the pious emulation of the lifestyles of the Prophet and his companions, and those who emphasize the importance of reform through the reasoned application of Islamic 
principles and beliefs. ${ }^{15}$ Palestine and the policies of the US preoccupy Arab intelligentsias and salon society. But the core political issues of the region, almost monopolized by Islamist political forces for want of a credible political alternative, are jobs, education, food security, honest government and justice.

The global struggle against terrorism has arguably done more to promote authoritarianism in Arab states friendly towards the West than it has done to support democratic change within them. The events of 11 September 2001 and their aftermath provided an excuse for further moves among Arab governments to limit civil and political freedoms. ${ }^{16}$ Those restrictions show little sign of easing. The fact that some regimes have agreed to the establishment of globally-networked civil society organizations in their countries is largely driven by a determination to control the potential impact of those bodies more effectively, although regimes may also find it convenient to point to their presence as evidence that their countries should be respected for acknowledging the benchmarks of a globalized world. Government-endorsed or sponsored organizations are not permitted to play a meaningful part in reform, an approach on the part of regimes which leaves civil society activists to decide whether to dance with the gaoler. Most choose to do so. ${ }^{17}$

As will be discussed, there are areas of economic reform in which Middle East Arab governments have made some headway, especially over the past decade. There is growing awareness in the Arab world that achieving viable and competitive economies 'requires a host of reforms. Banking systems, contract laws, courts that adjudicate commercial cases, and the way in which bureaucrats deal with foreign investors all need to be overhauled, as does the education system in many cases'.$^{18}$ The implantation, over an extended period, of new business models and values may help to provide the basis for solutions in the longer term to the current challenges of unemployment and government underperformance. But both in terms of the degree of institutional change that has been achieved, and so far as the values underlying such change are concerned, reform has been both uneven and limited.

Arab authoritarianism may have become less heavy-handed, at least in some respects, with the generational changes of recent years, but the dominant political values of the region's elites are not showing much sign of yielding to internal pressures for change. Egypt has remained under a state of emergency since 1981; Syria since 1963. ${ }^{19}$ As Charles Tripp, Toby Dodge and others have argued, in the short to medium term, political logic shapes the calculations of rulers more than the urgings of reformists, or the long-term economic logic that theories of globalization assume. ${ }^{20}$ 
Moreover, as Ottaway and Dunne note, there is no agreement about the role of political reform in these processes of economic revitalization. ${ }^{21}$ The role of political leadership in building support for sustainable processes of change is obviously vital. Politicians are responsible for communicating the need for reform, its benefits and the cost of inaction. Building trust in governments, ventilating issues and options through the media and demonstrating receptivity to ideas and feedback all help to provide legitimacy to government decisions. But achieving those outcomes requires level political playing fields, political transparency, acceptance of competition, tolerance of diversity, and media freedoms which are still often absent. Cross-cutting issues such as gender, consumer rights, and environmental management also present potential challenges as the reform process progresses.

Pressure is growing for the problems facing Egypt and other Arab Middle East countries to be met in a much shorter timeframe than incremental change alone would permit. And mere words will not fulfil the needs of a region in which, as Fred Halliday has observed, there is 'a crisis of political legitimacy, after decades of hot air and rhetoric - from nationalists and Marxists, Maoists and Islamists, and now Worldbankists and globalists'. ${ }^{22}$ Although in July 2006 US President George W. Bush spoke of the creation of a new moment of opportunity in the history of the Middle East, it remains to be seen for whom this moment of opportunity was created. ${ }^{23}$

\section{THE ISSUES}

Against that rather sombre background, this book seeks to examine factors driving social and political change, and resistance to change, primarily in Egypt, and to a lesser extent in Syria and Jordan. Arab analysts have recognized for much of the current decade that authoritarian rule is a key constraint facing efforts to realize the full potential of the Arab world, to harness the intelligence and vision of its people, and to meet demands of rising consumer expectations and infrastructure requirements. But in recent years, the economies of most Arab countries have shown strong evidence of both growth and reform, while political reform has been much less apparent.

In that regard, the core issue of the book concerns the extent to which, over the coming decade, globalization is likely to make a causal connection between economic change and, in due course, social change and political reform. The progress which has been achieved in the Arab Middle East in recent years is directly related to factors such as demographic pressures 
and rising levels of education and literacy. But will the processes of political and social change gather momentum under the auspices of globalization, especially its economic reform dimension? The book will also touch upon three contemporary issues - Islam, Israel/Palestine and Iran - which contextualize and add yeast to the fermenting brew of structural issues facing the region.

\section{CONCEPTUAL APPROACH}

The main conceptual framework for the analysis undertaken in this book is the notion of globalization. However, it is necessarily an approach taken with some misgivings and qualifications.

From one perspective, external intervention in the Arab Middle East is a recurring part of its history and a key element in shaping the region in the contemporary era. As Fred Halliday has observed, engagement with the West on unequal and conflictual terms has shaped the contemporary Middle East. ${ }^{24}$ And, despite its imprecision, the somewhat simplistic notion of an Arab and Islamic world failing to cope with the challenges of rising global interdependence and engagement with 'the West' has significantly shaped perceptions of the Arab Middle East among commentators on the Arab world..$^{25}$ It has influenced the attitudes and behaviour towards the region of various external players - including investors, multilateral financial institutions, journalists and human rights activists.

On the other hand in the Middle East context the notion of globalization may be misleading and open to intellectual abuse. It has a degree of empirical weakness, in that the stage has not yet been reached where it is possible to speak in meaningful terms of popular Arab participation in global society, or of the people of the Arab Middle East in general being part of a framework of worldwide social relations. Globalization is having an impact on Arab society in many ways. But beyond a sense of shared Arab identity, it is only in some specific respects - notably in regard to the global networking of certain streams within Islamism, and among some elements of the modern middle class - that there is arguably much evidence of a sense of interdependence and commonality at a global level between the populations of the Arab Middle East and non-Arab citizens of other countries.

Also of concern, where globalization is used as an analytical framework, is the tendency in some quarters to use the notion that there is a contest between globalization and resistance to change as a framework for discussion and explanation of 'what went wrong' with the region, and what needs to be done within the Arab Middle East for it to be part of a 
process which will carry populations to levels of achievement comparable with developed countries. ${ }^{26}$ Some of that analysis - notably that undertaken by Arab analysts in the United Nations Development Programme (UNDP) Arab Human Development Report series and an excellent analysis by the Brookings Project on US Relations with the Islamic World ${ }^{27}-$ has been constructive, insightful and attuned to the structural nature of the challenges facing the region. However in the heady environment of strong global economic growth and the ascendancy of western strategic power and political influence of the 1990s there also appeared to be a sense of advocacy, occasionally bordering on triumphal and brutal selfrighteousness among some analysts of globalization. ${ }^{28}$

Francis Fukuyama famously argued in 1992 that the power of market forces would result in liberal democracy replacing all other forms of government - the so-called 'end of history' thesis. ${ }^{29}$ Martin Wolf argued that globalization was 'at least as much a choice as a destiny' for states because, in his view, policy choices would determine the pace and depth of the integration of countries into the global economic system. ${ }^{30}$ So far as the performance of the Arab world was concerned, Hilal Khashan bluntly stated that 'failure to comprehend globalization leads inexorably to regional failure: the deterioration in the position of Arab countries vis$\grave{a}$-vis their non-Arab neighbours reveals advanced political decay and an utter inability to determine their destinies' ${ }^{31}$

Marc Lynch has observed that the enthusiasm with which the first UNDP Arab Human Development Report, launched in 2002, ${ }^{32}$ was received in particular among US neoconservatives 'was driven in large part by the post-September 11 fixation on the pathologies of the Arab world - and the conviction that it was these woes, not American foreign policy, that were the primary causes of terrorism'.$^{33}$ US political and academic commentators advocating regime change in Iraq including Fouad Ajami, Thomas Friedman and the neo-conservative Michael Ledeen drew on beliefs concerning the global applicability of liberal democratic values in arguing the case for transformational approaches to the Arab world and Iran. ${ }^{34}$

The empirical and conceptual inadequacies of much of that discourse - not least the limited appreciation of some commentators of the complicated dynamics of the Arab world and the reasons for popular Arab anger towards the US - underlines the need for caution where discussion of globalization is extended to include policy advocacy. As a conceptual tool, globalization is only as useful as the insight it brings into the dynamics and consequences of change.

The approach taken in this book will mostly focus on the social and political consequences of globalization. There are of course good reasons for emphasizing the economic dimension of globalization, including 
the changing role of governments; the waxing or waning of the power of states; creation of new business opportunities, risks and rewards; the global consequences of financial crises; technology and capital transfers from high-wage to low-wage countries, and the growth of exports from developing countries to developed ones. It can be extended to include the impact of environmental changes, and the movements of people, both of which have a great deal of relevance to the Arab Middle East.

Approaching globalization from an economic interdependence perspective also helpfully highlights the implications for the Middle East of the global production of goods and services, especially under the auspices of transnational corporations. It focusses on the challenges sometimes posed by globalization to national sovereignty in the international economic arena. If viewed mainly as a process between states or national domains (which some would see as a separate phenomenon of 'internationalization' rather than globalization ${ }^{35}$ ) it is a process whose effects will be conditioned by the economic and political power and self-interest of the major economies which largely shape the outcomes of policy debates in global institutions which emerged in the aftermath of the Second World War. ${ }^{36}$

Viewing globalization as a process characterized by rapidly rising levels of interdependence between countries also captures an important point - the sheer velocity of technological and other forms of change that are taking place across the globe. Contact between countries - globalism - is long established but it was narrowly-based until relatively recently. It was to be found in trade links, colonial domination and other ties, but it was inclined to be bilaterally-focussed, or shaped by particular historical, strategic or political associations. Globalization represents a relatively recent 'thickening' of globalism - faster, cheaper and deeper - assisted by more rapid communications and the liberalization of trade and investment flows. $^{37}$

However treating globalization, in the Middle East context at least, mainly as an economic phenomenon has important drawbacks. Gaps between Arab economic performance and that of more developed countries in a globalizing world require explanation in terms beyond a strictly economic framework. It is important to capture adequately the political discourse, presumptions and suspicions generated, at least in the Arab context, by the advocates of political and economic norms of supposedly universal value. As the Arab authors of the Arab Human Development Report series have consistently and courageously acknowledged, shortfalls in political and social freedom, knowledge transfers, ideas and creativity, and the lack of empowerment of women are key concerns and reasons why the Arab world has failed to fulfil its economic potential.

While economic factors are obviously important drivers of change, they 
also do not explain adequately the impact of the key preoccupations of economic reform - with competitiveness, concern for cost-efficiency, real cost charging, individual creativity and profit maximization - upon the norms, values, political mythologies and other structural aspects of the Arab world. Nor do they shed much light on the resilience of the state in the Arab Middle East ${ }^{38}$, an issue which demands attention because the region represents an important example of the power of ideas and values to affect national goals and policies; to influence attitudes to change at government and popular levels; and to shape the behaviour of the state as a mediator of those processes.

Like responses among many developing countries, Arab Middle East economic, social and political responses to globalization reflect complex mixtures of aspirations, real and imagined historical experience and strongly-held social and political concerns. It is precisely the weight of such concerns, as manifested in the context of Palestine, that led the Syrian poet Nizar Qabbani to write in 1997 that he was 'with terrorism as long as this new world order is shared between America and Israel, halfhalf ${ }^{39}$ Nationalism, Islamic identity and colonial legacies will continue to play their parts in shaping reactions to globalization, in addition to the questions raised about the phenomenon's economic aspects. ${ }^{40}$

Arab Middle East experience bears out the observation of Robert Keohane and Joseph Nye that the effects of globalization vary with the size, power and domestic political culture of states. ${ }^{41}$ Focussing on globalization as mainly an economic phenomenon risks leading us away from important questions - for this book at least - about the extent to which the values and expectations generated by globalization in all its dimensions are fragmenting nation states at the political and social level. For many, globalization is as threatening as it is enticing, 'an unequal process and one that generates increasing difference'.$^{42}$ Nor does a predominantly economic focus provide much insight into whether, and how, such social and political fragmentation may be addressed.

It is therefore the impact of globalization upon political culture which provides a key focus for this book. Unlike those who begin with an assumption that globalization and democratization are normative factors which embody some sort of historical destiny or performance benchmark for civilized mankind, this study takes as its starting point the resilience of the Arab state, the ongoing strength of the political status quo and the determination of the established Arab system to defend itself, during the process of economic reform, from pressures for transparency, accountability and political reform. It acknowledges that globalization is playing a part in shaping the region. But it also makes the point that the influence of globalization on political culture varies because of the lack of integration 
within Arab society, and the strength of informal networks acting to preserve their privileges. It also emphasizes resistance to change at the societal level as a structural issue facing reformists, while pointing to trends that are likely to reduce that resistance over the coming decade.

\section{STRUCTURE}

Chapter 1 lays the conceptual groundwork for the book. It discusses what globalization represents in the Middle East context, the main avenues through which it is having an effect, and some necessary qualifications to generalized assessments of its impact. The aim, it suggests, should be not only to investigate the influence of the economic reform processes falling under the heading of globalization, but also to capture adequately the sensitivities, discourse, presumptions and suspicions generated, at least in the Arab context, by the advocates of political and economic norms of supposedly universal value. It also questions the extent to which empowerment alone may provide answers to emerging challenges.

Chapter 2 examines the nature of contemporary Arab Middle East society. The main contention of the chapter is that limited integration within Arab society between leaders, middle class and popular society, and the strength of informal networks as well as formal institutions in defending privilege and resisting change has produced varying responses to the pressures and opportunities of globalization. The analysis draws attention to the importance of effective political leadership and communication in addressing those issues.

Pursuing that theme, Chapter 3 looks at the political context of globalization and the challenges to reform in the specific case of Egypt, a country which brings into focus the interaction between many of the pressures for and against change in the Arab Middle East. As well as encapsulating the factors which make change both necessary and possible, Egypt provides evidence of both adaptation and resistance to those processes.

Chapter 4 discusses the role of Islam in shaping societal and political responses to change. It examines Islam from a range of perspectives, hoping to draw conclusions as to whether Islam will support or constrain efforts to integrate Egypt and the Arab Middle East region more closely into the globalized world. It argues on balance against the deliberate and formal exclusion of Islam from political life, not least because those processes are damaging the reform process as a whole. It also notes that inter-generational tension and frustration is evident in Islamist as well as secular political circles: both streams will confront difficult choices in coming years. 
The outlook for political reform and empowerment will be shaped to a considerable extent by the sustainability of the economic reform process. Accordingly, Chapter 5 examines economic reform and the extent to which social and political values may be affected by changing business models in the region, highlighting the challenges in making progress towards social reform in authoritarian societies lacking strong vertical integration. It discusses the impact of economic and business reform on gender roles, and the relationship between governments and marginalized groups in the context of economic change.

Chapter 6 reviews the issues and arguments, and attempts to look at trends over the coming decade. It evaluates the drivers of change in a regional context, and considers the role political and security issues might play in shaping the outlook for reform. It concludes with some comments on external parties and their role in supporting the reform process. It then seeks to answer the question of whether economic reform and globalization is capable of prevailing over the defence of existing privileges and other factors which help to preserve the status quo; and if so, whether the quality of political leadership will end up being sufficient to bring about that outcome.

\section{OPTIMISTS AND PESSIMISTS}

The chapters which follow present evidence for both optimism and pessimism, somewhat reminiscent of the old joke that a Middle East optimist is someone who believes today will be better than tomorrow. The pessimistic view would argue that the outlook for the Arab Middle East can only get worse, as remaining oil reserves in Egypt and Syria are depleted, populations grow and social and economic gaps widen. Some might argue that, as it took the crisis of defeat and loss of empire following the First World War to galvanize the Turks into building a modern and capable nation state, so too will it take just as serious a crisis for the Arab Middle East states to get their houses in order and to succeed in achieving the exponential growth required to keep pace with a globalizing world. Military defeat at the hands of Israel in 1967 did not produce such a response. Two generations later, the Arab Middle East is still struggling to resolve some fundamental questions.

Optimists, including this author, acknowledge that further crises are indeed possible, perhaps producing not progress, but stagnation and fragmentation as people cast around for new ideas, or hark back to old ones, rather than trying to address critically and practically the fundamental political and social sources of their frustration. But such concerns should 
not lead us to discount too readily the changes that are occurring, and the determination of reformers to rise to meet the challenges ahead, both domestic and external.

This book is also a study of the capacity of leaders to make difficult decisions, and to implement them. It does not seek to predict whether those decisions will in fact be made. There are too many variables attached to regional politics to permit one to move with even modest confidence beyond the explanatory function of social science into the far more hazardous business of prediction, and speculating about what course the region will take would be unlikely to contribute in any constructive way to discussion of present realities. The more important issue, from a social science perspective, is whether credible and exemplary political leadership can manage the tensions and anxieties within those societies as the drivers of change press relentlessly forward.

Whether transformative decisions are made or not, however, the underlying forces for change within the region are unstoppable. Education, demographic changes, enhanced communications and changing business models are all inescapably part of the region's future. The drivers of change may be indirect, subtle and difficult to observe and measure in the flow of daily life, but the gaps within Arab societies will widen substantially, as different parts of those societies respond at different rates to domestic and external stimuli.

Frictions will have to be managed between those whose economic, social and political interests are protected by formal and informal networks of privilege and those demanding - and growing increasingly capable of pursuing - an alternative, empowered future. If left unaddressed, the consequences arising from those tensions are potentially akin to a tsunami-like current of instability and regression moving towards a largely unsuspecting shoreline..$^{43}$

It will be argued that on balance, there is a stronger case for optimism than for pessimism about the direction Egypt and the other Arab Middle East countries may take over the coming decade of accelerating transition. Many other countries are changing faster than those of the Arab Middle East. But the recent record, and emerging trends in Egypt and among other Arab states discussed in this book suggest that they too will continue to achieve at least modest economic progress.

It is a tall order, but those Arab leaders - and most especially the leaders of Egypt - who come forward with evidence that they can provide paths to higher standards of living, and opportunities for an emerging generation to be part of a 'modern' Arab world, still have a fair chance of constructively shaping the direction of their countries over the coming decade.

The challenge will be to overcome economic, social and political 
resistance to a process which may largely strip away, over time, the comforts of authority and privilege which have long been part of the Arab Middle East. Reform is set to challenge and perhaps change traditional values of conformity and predictability that have been embedded in Arab society and government alike.

Because the alternatives are worse, leaders have to find a means of sustaining that process of change. But they will face the task of doing so within institutional frameworks, both formal and informal, that are mostly nervous about reform. And they will have to find a basis for engaging positively with sceptical and anxious audiences, many of whom will be longing for security and personal dignity in a social and economic environment which is evolving in directions which only a generation ago were unimaginable.

\section{NOTES}

1. Bubalo, Fealy and Mason (2008) p. 4.

2. Karoui (2006).

3. For an excellent discussion of these trends see Hourani (1991). The changes are also captured by the Egyptian novelist Naguib Mahfouz. See Mahfouz (2001).

4. Rubin (2006), pp. 81-2.

5. Dodge and Higgott (2002); Halliday (2002).

6. UNDP (2009), pp. 139-40.

7. Stepan (2003), pp. 39-42.

8. Hamzawy and Brown (2007).

9. Lord (2008).

10. Ottaway and Dunne (2007), p. 3.

11. The Economist (2009d).

12. Ottaway and Dunne (2007), p. 4.

13. The Economist (2009e).

14. The Economist (2009a).

15. Crooke (2009).

16. UNDP (2003), p. 2.

17. Ottaway (2003), Phillips (2008).

18. Ottaway and Dunne (2007), p. 3.

19. UNDP (2009), p. 61.

20. Dodge (2002), p. 175. See also Tripp (2000), pp. 225-9.

21. Ottaway and Dunne (2007), p. 3.

22. Halliday (2004), p. 7.

23. 'This moment of conflict in the Middle East is painful and tragic. Yet it is also a moment of opportunity for broader change in the region. Transforming countries that have suffered decades of tyranny and violence is difficult, and it will take time to achieve. But the consequences will be profound - for our country and the world. When the Middle East grows in liberty and democracy, it will also grow in peace, and that will make America and all free nations more secure.' President George W. Bush (2006).

24. Halliday (2002), pp. 36-8.

25. Time magazine identified the Arab Human Development Report 2002 as the most important publication of 2002.

26. The range of literature addressing this issue directly and indirectly is vast. It includes 
a range of publications by the World Bank, International Monetary Fund (IMF) and UNDP including the Arab Human Development Report series.

27. Lord (2008).

28. Hoffman (2002), pp. 105-6.

29. Fukuyama (1993).

30. Wolf (2001), p. 190. According to Wolf, 'countries choose integration because they can see its benefits'.

31. Khashan (2000a), p. 49.

32. UNDP (2002).

33. Lynch (2009).

34. Fouad Ajami (2003) claimed that tyrannical Arab regimes, rejection of modernity and individual rights, rigidly hierarchical social structures, and lack of freedom had produced what he called the '[anti-American] road rage of a culture yet to take responsibility for its self-inflicted wounds'. Thomas Friedman (2002) wrote 'I am for invading Iraq only if we think that doing so can bring about regime change and democratization. Because what the Arab world desperately needs is a model that works - a progressive Arab regime that by its sheer existence would create pressure and inspiration for gradual democratization and modernization around the region.' Michael Ledeen (2002) wrote 'We should be talking about using all our political, moral and military genius to support a vast democratic revolution to liberate all the peoples of the Middle East from tyranny. That is our real mission, the essence of the war in which we are engaged, and the proper subject of national debate. . And just as a successful democratic revolution in Iran would inspire the Iraqis to join us to remove Saddam, it is impossible to imagine that the Iranian people would tolerate tyranny in their own country once freedom had come to Iraq. Syria would follow in short order.'

35. Scholte (2001), p. 15.

36. Those frameworks include, notably, the General Agreement on Tariffs and Trade (GATT) which later became the World Trade Organization (WTO), the IMF, the World Bank, and a range of trade agreements among major developed countries.

37. Nye and Keohane (2000), pp. 7-12.

38. Tripp (2000), p. 227.

39. Qabbani (1997).

40. Halliday (2002), pp. 41-2.

41. Nye and Keohane (2000), p. 17.

42. Halliday (2002), p. 39.

43. Lewis Lapham commented in the aftermath of the events of 11 September 2001 that 'We didn't see the planes coming because we didn't think we had to look.' Lapham (2001). 